\title{
Nominalized Matter: Generative Textiles Procedures
}

\author{
Daniel Baerlecken \\ Georgia Institute of Technology \\ daniel.baerlecken@coa.gatech.edu \\ Katherine Wright Johnson \\ Georgia Institute of Technology \\ kwright34@gatech.edu
}

\begin{abstract}
This paper investigates making as a process that brings together diverse materials and combines their flow in anticipation of what might emerge. Ingold calls this approach the textility of making, which gives priority to the formation of materials as a process, in which form is generated through interventions within fields of forces and currents of materials and not through a predefined notion of an ideal outcomei, opposes the Aristotelian "hylomorphic approach" which focuses on final products.
\end{abstract}

Keywords: Analogue computing; Craft; Design methodologies; Form finding; Textiles

\section{Introduction}

This paper investigates digital and analogue making as a design process, bringing together diverse materials and combining their flow in anticipation of what might emerge. This method opposes the Aristotelian, hylomorphic approach, which focuses on the goal state of the product. Tim Ingold calls this method the "textility of making" (2009). Priority is given to the process of material formations, which govern the sequence of design decisions. Form is generated through interventions within fields of forces and currents of materials, not through a predefined notion of an ideal outcome. All materials, when sufficiently mobilized, find ways to organize themselves. In vernacular structures (textile techniques) similar ways are found to create patterns, where materials are allowed to be flexible and to configure step by step into a final shape.

In a sequence of design studios, textile techniques investigate the potential for creating novel architecture systems where ornament and structure perform as one. This paper presents examples of this method applied to solving an architectural design problem, ranging from a Semperian approach (wall as dress) to form finding experiments with active textile material machines (Otto, 1995).

\section{Methodology}

The methodology of the studio is based on a systematic procedure that Lars Spuybroek has developed and documented in the $R+D$ series (Spuybroek 2009, Spuybroek 2012). The investigation proceeds in phases, where materials are used for an exploration, which starts with flexible threads (from yarn to plastic tubes to wood fibers) and transitions into flexible strips (from paper to cardboard to wood) or to rigid sticks (wood) or to flexible surfaces (from rubber, to textile to paper). The three phases are:
Phase I: Textile systems are researched through understanding figures. Figures configure into more complex configurations and are studied through material studies.

Phase II: The flat nets are thickened or multiplied. More complex operations such as deformation and transformation are explored.

Phase III: The spatial and structural effects are studied and developed.

The intention is to introduce a solution to the problem of transferring diagrams into architectural form through material exploration.

\section{Techniques}

Materials are allowed a certain amount of freedom to act as agents and process forces in order to configure into a more structural state. The term "analogue computing" is linked to Frei Otto's experiments on form finding and Gaudi's catenary techniques, but can also be applied to Semper's "Stoffwechselthese", where one material system informs another. Along with his Stoffwechselthese theory of dressing (Bekleidungstheorie), Semper proposes his theory of the four elements of architecture: the earthwork, wooden frame, the textile membrane, and the hearth. Semper emphasizes the performance of the textile membrane through his "theory of dressing" stating aesthetic performance of the wall through ornamentation over structural performance (Frampton, 1995). For Semper architecture has its origins in textiles, specifically in weaving and braiding, through the light and highly ornate nomad 
tent architecture. Subsequently, Semper contrasts two types of enclosure: (a) die "Mauer" and (b) "die Wand". Both mean "wall" but the "Mauer" is a fortified, solid, monolithic wall serving to create security. In German "Wand" can be linked etymologically to Ge-wand, dress. So the "wand" is a type of enclosure that is a light textile carpet in the likeness of a screen-like wickerwork or an ornate dress. The second Semperian theory, the Stoffwechselthese, is highlighted in our work. We see technique develop where one material is transferred to another substance as a Semperian example of the textile transferred through stone carving.

Techniques that will be discussed in this paper include felting, knitting, weaving, draping, wettening, and combining.

\section{Felting}

Felt is a non-woven textile that is produced by pressing fibers together into mats. Starting with the study of different felting techniques such as wet felting (natural wool fibers are stimulated by friction and by soap to make tacking stitches)
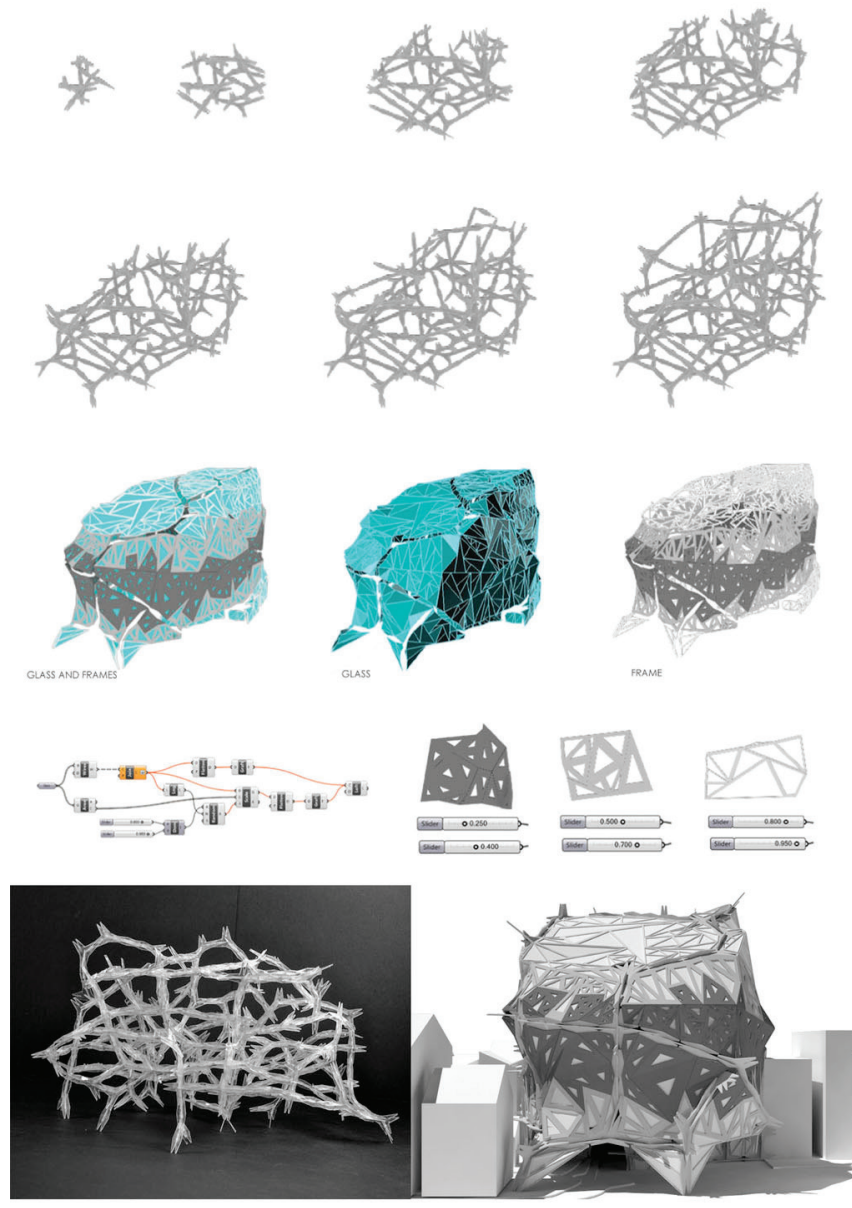

Figure 1: Felting of rigid structural components and panelization and needle felting (through the use of a needle, layers of felt are stitched together without the use of water), a derivative felting technique is developed as the interlocking of loose figures, that perform in analogy to fibers, to create an ornate structure (Figure 1).

The study explores the structural system as an opportunity to create interconnected volumes based on a limited set of figures, which perform aesthetically as spiky knots linking columns and beams. The variation of knots, columns, and beams create a crystalline structure that can adapt to the different forces of program and site.

\section{Knitting}

Knitting is a technique that uses yarn to create consecutive rows of loops, which secure each other in the process of making. The study focuses on different surfaces types in order to increase structural properties of the system and to create spatial enclosure: from flat surfaces over twisted surfaces and single curvature to open surface to enclosed cylindrical surfaces. Figure 2 shows the transfer of the knitted soft structure made using the tradition of yarn (a continuous string) to a rigid structure made from one block type - both ornamental and structural at the same time.
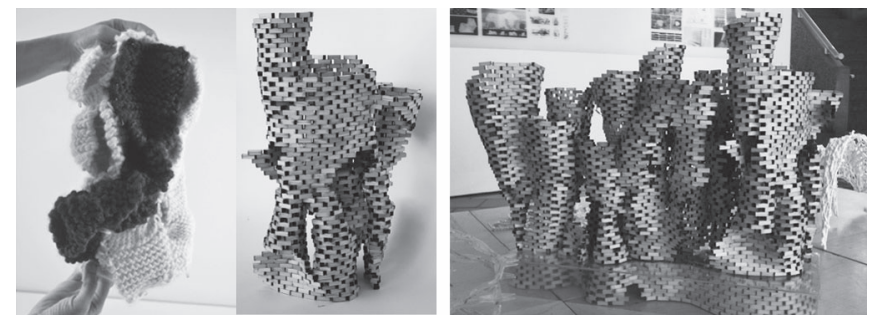

Figure 2: Knitting explorations with yarn transfer to one block type

\section{Weaving}

Weaving is a technique that works from a loom with elements fixed in one direction. The computing machine (loom) for the study in Figure 3 is blended with two analogue computing techniques. Here a network of fibers are softly structured in a rectilinear swatch of a woven pattern, which is then dipped into a water and plaster solution. The soft structure is coated by the solution, creating additional weight and freedom for movement.

After the dip the soft structures are hung upside down from a horizontally braced frame. The weight of the solution and the addition of nodal weights create force and movement to a soft flexible material system (similar to Gaudi's catenary structures). The sequence of images shown above (Figure 3) documents this exploratory process as research with the first column cataloguing the soft surface prior to the dip next to the diagram of the surface, which presents the location and quantity of weight placed on the system. 


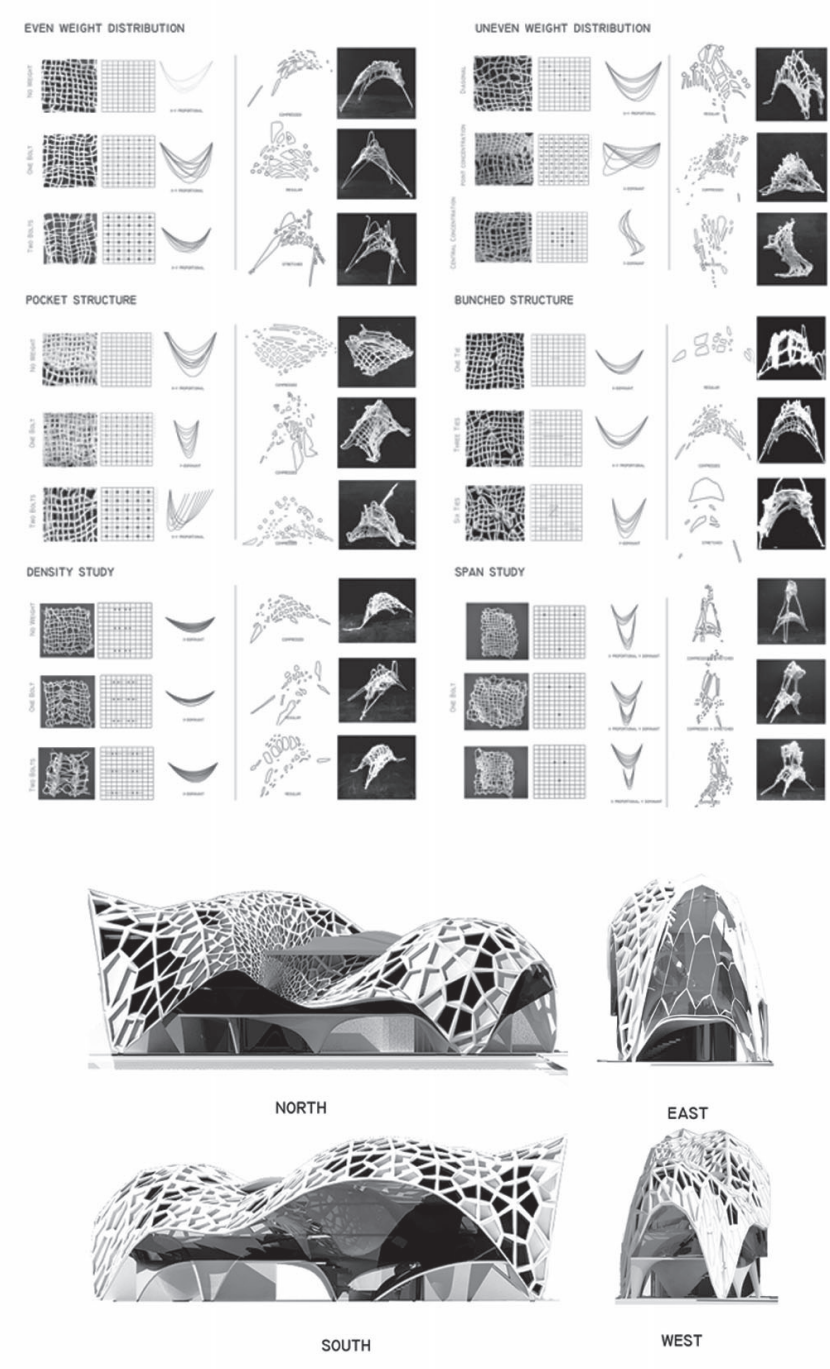

Figure 3: Weaving

The system's curvature is documented (third row) as the model hangs upside down. After the solution hardens, making the system rigid, the model is cut from its frame and flipped. The last two rows present the final model in its rigid state and a diagram of apertures. Students observed the systems preference for bundling and separating of "structural ribs" as the possibilities for curvature are explored.

\section{Wettening}

Otto's material machines ("optimized path systems") were devised to test complex material behavior, reorganizing the system by introducing one material with another, creating a transformation of the material system. As material machines restructure themselves through interactions among elements in a restricted time, the material "finds [a] form". The material forces by transformation, compute interactions and resolve geometries. Wettening is a technique used to configure flexible elements (ex. wool thread) through sticking. In one study students explored wettening as a method to compute an architectural structure. A material machine is developed as a dipping mechanism that allows submerging a matrix of wool threads under water (Figure 5).

The machine is setup as two planar grids: one positioned at the bottom and one at the top of the apparatus. Threads connect from the lower to upper grid. Each of the thread has a slack of $4 \%, 6 \%$ or $8 \%$ depending on the scenario of the experiment. During the dipping process the slack allows the threads to bundle, split and network to optimize paths. The system transitions from individual, linear, inactive members (before dipping) to a network with branching and crossing (during dipping). The results range from structural surfaces to a spatial structural systems depending on the initial setup ( the number of rows and the amount of slack influence the networking behavior).

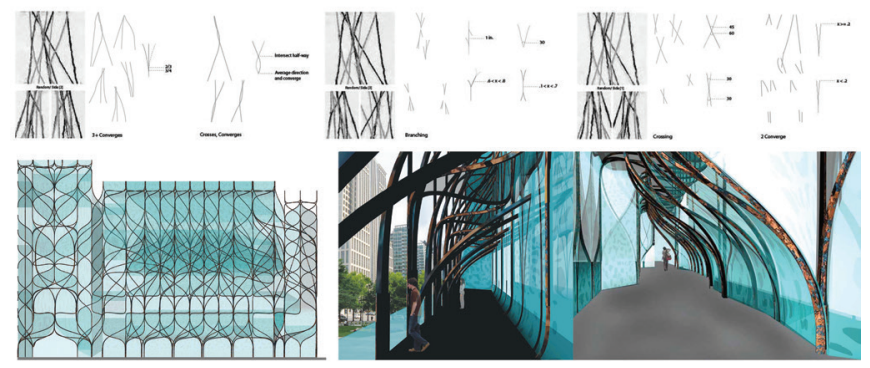

Figure 4: Wettening

\section{Draping}

Draping is a carefully planned operation of dressing a figure or a group of figures in paintings and sculptures. Winkelmann describes drapery as the echo of the body, that allows perceiving form and movement of the body at the same time. In draping we can perceive these two antipodes: moments where the body is rendered visible and simmers through and moments where forces of movement, gravity or other external forces form an intricate, autonomous play of lines and volume. The first type we can observe in Roman and Greek sculpture, where the technique of wet draping is used to freeze the folds in their position. Herder describes the wet dress as a method in Greek sculptures that allows to resolve the contradiction of dressed nakedness by showing a body in an encasing mist (umhuellender Nebel). This type of wet draping can be found for example in three female figures at east pediment of the Parthenon: the bodies appear dressed and naked at the same time.

This principle is diametrically opposed to the second type, where autonomous folds form over a body, as in Bernini's The Ecstasy of Saint Teresa.

Herder further makes a distinction between sculpture and painting. He emphasizes that in paintings the body is secondary and the texture/ patterning of the dress acquires dominance over the body. 

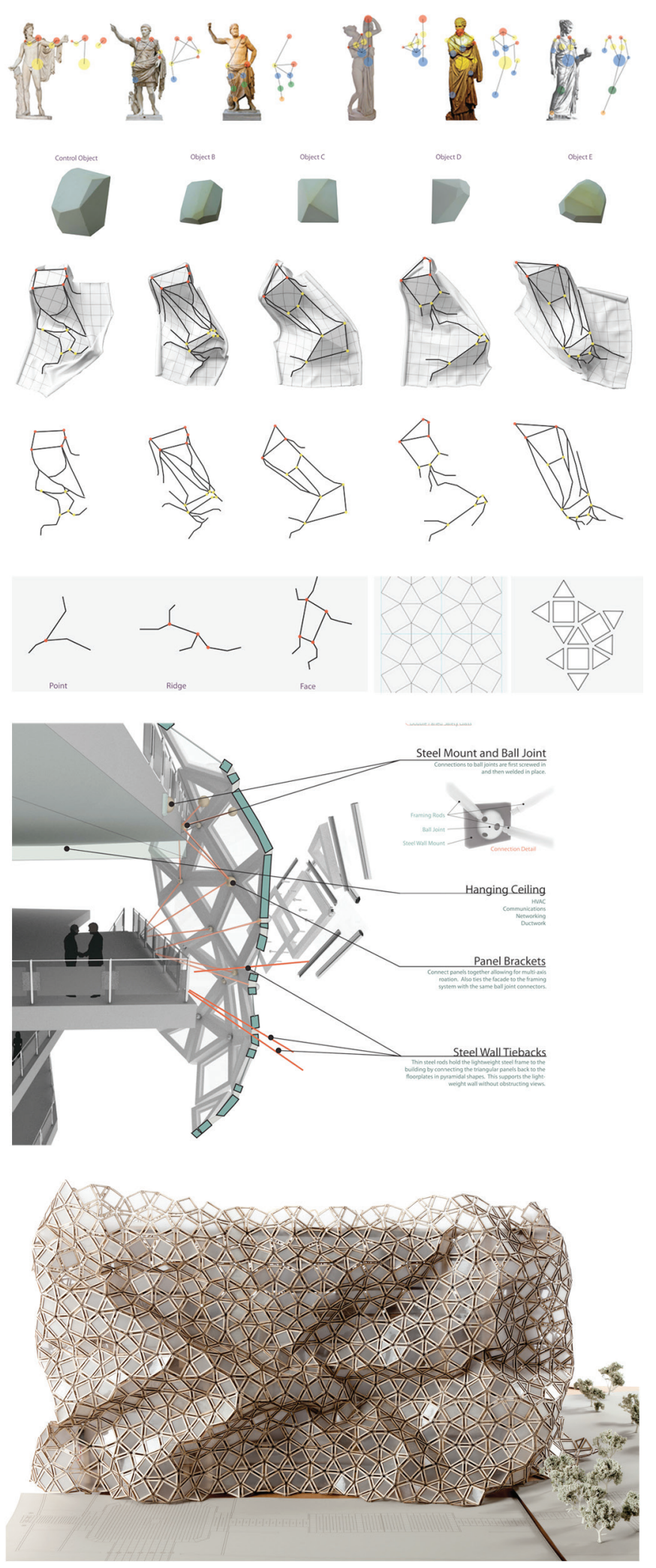

Figure 5: Draping

The presented project combines wet draping (Figure 4) with as a technique with a tessellation pattern of triangles and quads, using both types of drapery (sculpture and painting) simultaneously.
Through the tessellation the surface locks into folds that bulge and pinch based on the distribution of quads that limit movement. The pattern following the program informs the behavior of the surface.

It follows the logic that Frei Otto used for the Mannheim Multihalle, where a grid shell is locked into a double curved, rigid surface. The grid shell is initially flat and joined together by pinned joints that allow parallel movements between laths. When the structure is erected as 3 dimensional shell, the double curvature of the shell achieves strength and stiffness.

Similar to Frei Otto's structure the draping project only requires a few fixed points to transition from a flat, flexible surface to a 3-dimensional surface with strength and stiffness.

\section{Combing}

The technique combing uses parallel elements to create a structure that bundles and splits like hair. The structural elements are combed or spaced out in different intervals. Hair as a material has isotropic properties. The presented project shows an exploration of anisotropic material using rectangular timber members. The anisotropic properties enable different structural and bending properties of each member.

Combing is used to organize the façade structure according to vistas and programmatic requirements. It always uses multiple, thin elements that come together to form a structural member.

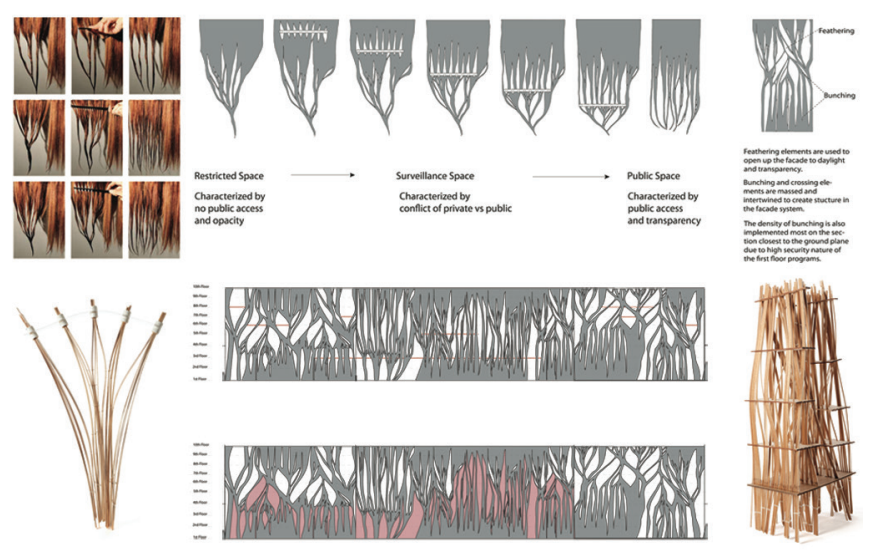

Figure 6: Combing

\section{Interlacing}

The last technique is interlacing, where linear elements are looped, braided and knotted to fill empty space between text blocks (Book of Kells), on rune stones or on Celtic crosses. The interlacing project studies Native American dream catchers, which are made from willow hoops as a loose net of nodal points. The 2dimensional dream catchers are developed into 3-dimensional tubes with a diagrid support structure that follows the original nodal logic of the dreamcatchers. In additional strategies to join multiple tubes into one tubes are studied and applied to a building proposal. 


\section{Conclusion}

Within this methodology the designer is a responsive agent, using his/her knowledge of built systems to direct the emergent results of the process through analogue and digital modes.

\section{Acknowledgments}

Felting project (Figure 1) by John Warrener; Knitting project (Figure 2) by Tianjing Guo; Weaving project (Figure 3) Kaleigh Sawyer and Stephanie Douthitt; Draping project (Figure 4) Luke Kvasnicka and Wesley Herr; Wettening project (Figure 5) by Catherine Quigley; Combing project (Figure 6) by Victoria Acevedo and Will McCollum.

\section{References}

Baerlecken, D. and Riether, G.: 2012, Aggregates: Digital design for design, CAADRIA2012, pp. 607-616
Baerlecken, D., Katherine, J., \& Alice, V. (2013). Mobilized Materials Textile Constructs. CAADRIA 2013, pp. 333-342

Frei Otto, Bodo Rasch: 1995, Finding Form : Towards an Architecture of the Minimal, Axel Menges, Germany.

Ingold, T., The textility of making (Oxford: Cambridge Journal of Economics, Vol 34, 2010) 91-102.

Spuybroek , L.(ed): 2011, Research \& Design: Textile Tectonics, NAI Publishers, Rotterdam.

Spuybroek, L. (ed): 2009, Research \& Design: The Architecture of Variation, Thames and Hudson, London.

Spuybroek, L. (2011). Sympathy of things : Ruskin and the ecology of design. [Rotterdam] New York, NY: V2 Publishing : NAi Publishing.

Frampton K., Studies in Tectonic Culture, The Poetics of Construction in Nineteenth and Twentieth Century Architecture, (Cambridge, MIT Press, 1995). 